\title{
A note on the potential impact of aviation emissions on jet stream propagation over the northern hemisphere
}

\author{
Magdalena Kossakowska ${ }^{1}$ (D) . Jacek W. Kaminski ${ }^{1,2}$
}

Received: 22 August 2019 / Accepted: 8 May 2020 / Published online: 29 May 2020

(c) The Author(s) 2020

\begin{abstract}
The goal of the study was to investigate if aviation emissions could influence the climate and weather by modifying the chemical composition of the atmosphere and subsequently, the radiative balance. To carry out the set objective, we used the global environmental multiscale atmospheric chemistry model with comprehensive tropospheric and stratospheric chemistry that is interactive with the radiation calculations. The model was run for two current climate scenarios, with and without aviation emissions. The results of the study indicate that the most significant difference in the jet stream propagation occurred during the winter season, and the smallest was observed during summer. Changes in the jet stream propagation vary by season and region. During the colder time of the year, the eddy-driven jet stream tends to shift poleward, while during the spring season the equatorward shift was observed in a scenario with aviation emissions. Analysis of regional changes shows that the most noticeable differences occurred over the Pacific Ocean, Atlantic Ocean and Asia. The changes over the oceans changed the occurrence of the North Pacific and Bermuda-Azores Highs. Over Asia (Siberia), a stronger and more poleward drift of the eddy-driven jet stream was observed in a scenario without aviation emission. Dissimilarity in the jet stream velocity was found only during the winter seasons when in a scenario with aviation emission, the jet stream velocity was $10 \mathrm{~m} / \mathrm{s}$ smaller as compared to the scenario without aviation emission.
\end{abstract}

Keywords Aviation emissions - Jet stream · Upper troposphere lower stratosphere - Global environmental multiscale atmospheric chemistry model (GEM-AC)

\section{Introduction}

One of the most significant regions of the atmosphere is the tropopause layer, called the upper troposphere and the lower stratosphere region (UTLS). UTLS is a transition layer where the boundary between the polluted troposphere and ozone-rich stratosphere lies. It plays an important role in tropospheric large scale circulation, stratosphere-troposphere exchange (STE) and the quasi-biennial oscillation (QBO) in the stratosphere (i.e. Holton 1995; Jensen et al. 1996; Garfinkel and Hartmann 2010; Forster and Shine 1997). Any changes in the chemical composition of this region will lead to changes in the dynamics through changes

Magdalena Kossakowska

mkossakowska@igf.edu.pl

1 Institute of Geophysics, Polish Academy of Sciences, Ksiecia Janusza 64 Street, 01-452 Warsaw, Poland

2 WxPrime Corporation, 21 St. Clair Ave East, Suite 1005, Toronto, ON M4T 1L9, Canada in the radiative processes (Brasseur et al. 2008; Gettelmann et al. 2011; Hegglin et al. 2010; Shepherd 2002, 2007).

Anthropogenic pollution has a significant impact on atmospheric composition in the troposphere. Most of the sources are near the ground. Thus, the majority of the chemical reactions will take place in the lower and the middle troposphere. Only inert and a small number of reactive species from the ground-based anthropogenic emissions reach the upper troposphere. The aviation emissions, on the other hand, are released mostly in the UTLS region (Olsen et al. 2013a, b). That may cause significant changes in the atmospheric chemistry near the tropopause, especially in the area of heavy airline traffic. Analysis of different aircrafts' fuel burn datasets indicates that $69.0 \%$ of aviation emissions are released over the mid-latitudes of the Northern Hemisphere (with the maximum at $40^{\circ} \mathrm{N}$ ), especially over North America (with maximum at $90^{\circ} \mathrm{W}$ ), Europe (maximum between $0^{\circ}$ and $10^{\circ} \mathrm{E}$ ) and East Asia (maximum over $115^{\circ} \mathrm{E}$ ). Almost $75 \%$ of aircrafts' fuel 
burn takes place in the UTLS, at the height of $7 \mathrm{~km}$ (Wilkerson et al. 2010; Olsen et al. 2013a, b).

The complex interactions of gaseous species, direct and indirect effects of aerosols, as well as aviation contrails on the atmospheric chemistry and microphysics, make it difficult to estimate the potential impact of aviation emissions on climate (Penner 1999 (IPCC); IPCC AR5 2014). Lee et al. $(2009,2010)$ estimated that for the year 2005 , aviation was responsible for about $3.5 \%$ of the total anthropogenic radiative forcing, including aviation inducted cloudiness. This contribution increases up to $4.9 \%$ with a range of $2 \%$ to $14 \%$ for a $90 \%$ likelihood range. Many studies show how sensitive modelling results are to aviation emissions and their changes in the UTLS region. For example, lowering flight altitude would lead to changes in the radiative forcing near the tropopause due to the increase in the upper troposphere's ozone mixing ratio. Increasing the fight altitude would lead to the injection of aviation emissions directly into the stratosphere that may have a significant influence on radiative processes (Frömming et al. 2012; Jacobson et al. 2012; Skowron et al. 2015; Søvde et al. 2014).

Most studies focusing on the impact of aviation emissions on climate calculate the global or regional climate change indicator like the mean temperature, radiative forcing or GWP100. However, available studies do not show the exact influence of aviation emissions on global circulation. In the presented study, we decided to examine the sensitivity of the jet stream propagation to aviation emissions, as an indicator of changes in global circulation. We can assume that due to changes in temperature over the Arctic (Yang et al. 2019; IPCC AR5, 2014; Jacobson et al. 2012) or in the low latitude upper troposphere (Grewe et al. 2002; Lee et al. 2010; Lund et al. 2017) there may be a noticeable change in the jet stream propagation that can strongly affect some regions, especially over the mid- and high latitudes (Barnes and Simpson 2017; Cohen et al. 2014; Linz et al. 2018; Xue et al. 2017). Studies suggest the general poleward shift of the eddy-driven jet stream (EDJ) as well as the subtropical jet stream (STJ), but those trends vary, depending on seasons or regions (Melamed-Turkosh et al. 2018; Rikus 2018; Strong and Davis 2007; Zolotov et al. 2018).

The tendency of the jet stream to poleward or equatorward shifts is mostly driven by the upper troposphere tropical warming (Sun et al. 2013; Simpson et al. 2012) and Arctic warming (Barnes and Simpson 2017), respectively. The Arctic warming will slow down the poleward jet stream shift due to GHG impact on low latitudes (Barnes and Polvani, 2013; Barners and Screen, 2015; Haigh et al. 2005; Linz et al. 2018). On the regional scale, the changes in the jet stream propagation may be influenced by sea surface temperature, ice cover, ENSO, stratospheric polar vortex, radiative forcing, QBO or volcanic eruptions (Hall et al. 2015).

\section{Method}

The objective of the presented study was to examine changes in jet stream propagation due to aviation emissions. We designed two current climate modelling scenarios: base scenario A0 without aviation emissions and scenario A1 with aviation emissions. We used the Global Environment Multiscale model GEM-AC with interactive and coupled tropospheric and stratospheric chemistry (de Grandpré et al. 2000; Kaminski et al. 2008; Mamun et al. 2013; Lupu et al. 2013). The model horizontal grid was defined as the global variable resolution from $3^{\circ} \times 3^{\circ}$ to $1.5^{\circ} \times 1.5^{\circ}$ zoomed over the high latitudes of the Northern Hemisphere, starting from $55^{\circ} \mathrm{N}$ (Fig. 1) with 70 hybrid vertical levels up to $0.1 \mathrm{hPa}$ and a 30 min time step and output set at every $6 \mathrm{~h}$. The vertical resolution in the UTLS region was $500 \mathrm{~m}$.

Both simulations were run in a climate mode setup for years 2001-2010. Both scenario runs were started with a "cold" model, allowing chemical species to balance in the atmosphere during the first 5 years of the simulation. Due to the model "cold" run, only results after 2005 could be analysed. Inventories of aviation emissions were available only for 2006, while for other years the aviation emissions were rescaled based on estimations provided by the International Civil Aviation Organisation (ICAO). In this paper, only results for the year 2006 are presented.

Climatological information is based on monthly mean ice cover and sea surface temperature, obtained from the geophysical fluid dynamics laboratory (GFDL) model. Historical anthropogenic emissions (excluded aviation) were taken from ACCMIP (Lamarque et al. 2012). Aviation emissions used in scenario A1 were from AEDT 2006 database provided as hourly $3 \mathrm{D}$ fields of the total fuel burn and $\mathrm{CO}, \mathrm{HC}$, $\mathrm{NO}_{\mathrm{x}}, \mathrm{PM}_{\mathrm{NV}}, \mathrm{PM}_{\mathrm{SO}}, \mathrm{PM}_{\mathrm{FO}}, \mathrm{CO}_{2}, \mathrm{H}_{2} \mathrm{O}, \mathrm{SO}_{\mathrm{x}}$ with horizontal of $1^{\circ} \times 1^{\circ}$ and $500 \mathrm{ft}$ in vertical (Kim et al. 2007; Wilkerson et al. 2010). The initial conditions for GEM-AC were generated using CMAM (de Grandpre et al. 2000, 2009).

For this study, the jet stream was defined as a narrow, horizontal air current with a wind speed greater than $25 \mathrm{~m} / \mathrm{s}$, located between 400 and $100 \mathrm{hPa}$. The definition is based on WMO's jet stream description (1958), and simple jet stream detection method proposed by Pena-Ortic et al. (2013) was used.

\section{Results}

Results for 2006 simulations with (scenario A1) and without (scenario A0) aviation emissions were analysed using the annual, seasonal (winter (DJF), spring (MAM), 

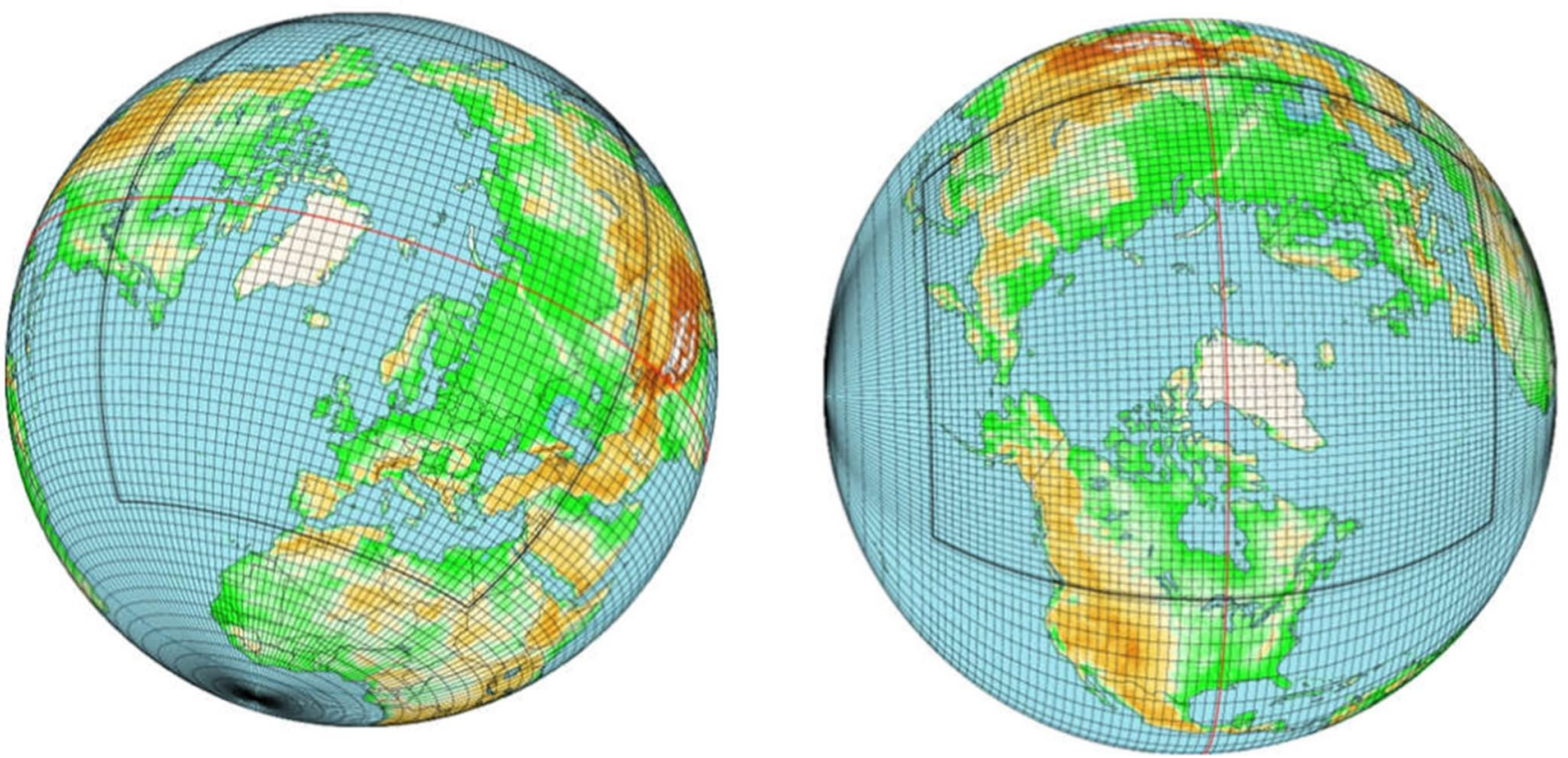

Fig. 1 Visualisation of the GEM-AC model grid with global variable horizontal resolution $3.0^{\circ} \times 3.0^{\circ}$ and $1.5^{\circ} \times 1.5^{\circ}$ regional nested over the Northern Hemisphere. European (left) and the North American (right) vantage point of view

summer (JJA), autumn (SON)) and monthly time interval averaging of the meridional and zonal wind velocities. For each period, we created three different visualizations:

W \& E hemisperic average for A1-A0_3x3_2006_YEAR

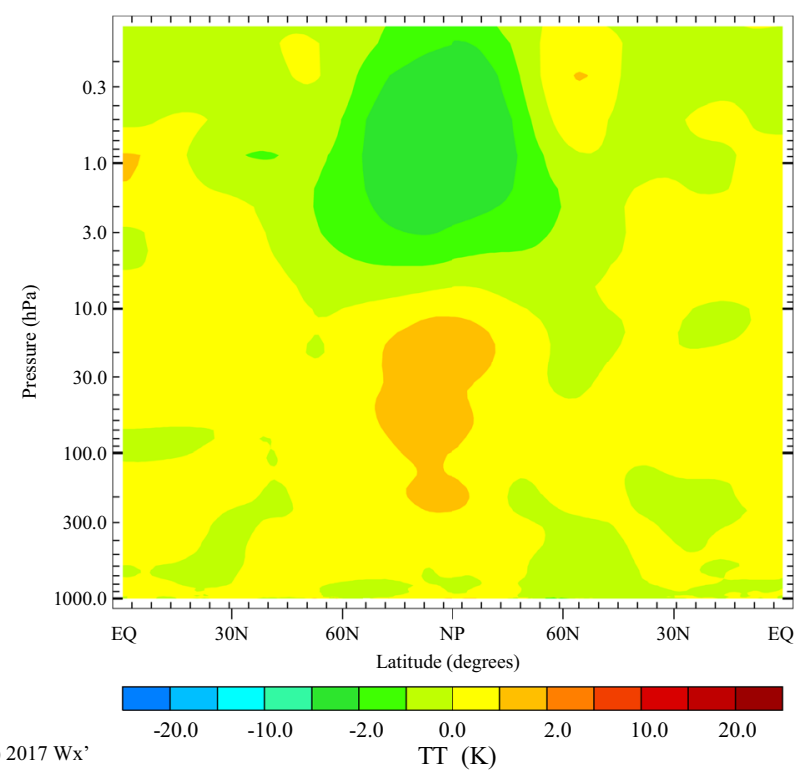

Fig. 2 Left: The difference between annual mean temperature between scenarios A1 and A0, averaged over longitudes, separately for Western (W) and Eastern half of the Northern Hemisphere. Right: average by longitudes, separately for Western and Eastern half of the Northern Hemisphere (shown in Fig. 2), average by latitudes in three bands: low (0-30), middle
Average latitude bands for A1-A0 3x3 2006 YEAR
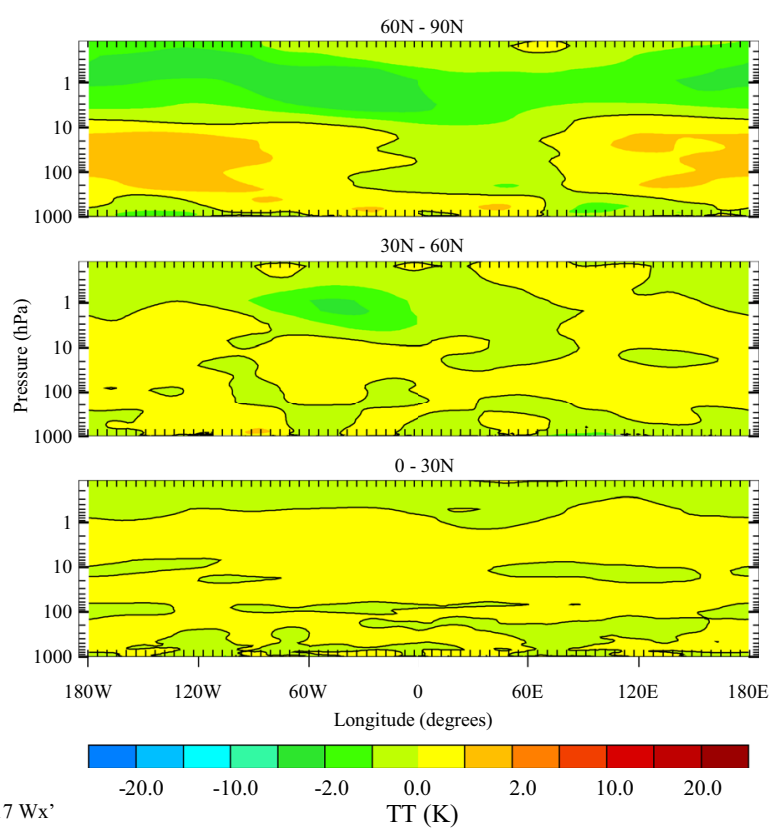

(c) $2017 \mathrm{Wx}$

The difference between annual mean temperature scenarios A1 and A0, averaged over latitudes for low $(0-30 \mathrm{~N})$, mid $(30-60 \mathrm{~N})$ and high (60-90 N) latitudes bands 
(30-60) and high (60-90) latitudes (shown in Fig. 2) and standard zonal average for the whole globe. The jet streams propagation was compared using monthly averaged wind velocity at several isobaric levels. Results for $250 \mathrm{hPa}$ level are shown as both the subtropical and eddy-driven jet streams. Also, we analysed changes in the temperature using analogical methods for the wind velocity to focus on changes of temperature, especially between high latitudes and low latitudes. We focused on changes in temperature near the ground over the polar regions, polar UTLS and the tropical upper troposphere transition layer (TTL).

\section{Changes in the temperature}

Analysing the differences between A1 and A0 scenarios' annual mean temperatures, we noticed that the largest changes occurred in the upper troposphere lower stratosphere region over the high latitudes, where scenario A1 shows a temperature that was $2 \mathrm{~K}$ higher (Fig. 2). On seasonal and monthly time scales, changes between scenarios were much larger. In the winter season, the influence of aviation emissions on temperature was the strongest over the lower troposphere of high latitudes, especially over the Arctic and Scandinavia, where the seasonal mean temperature in scenario $\mathrm{A} 1$ was $4 \mathrm{~K}$ higher than in scenario A0 (shown in Fig. 3), and the monthly differences vary from $3 \mathrm{~K}$ up to $8 \mathrm{~K}$. Also, we noticed regions with significant negative

W \& E hemisperic average for A1-A0_3x3_2006_DJF

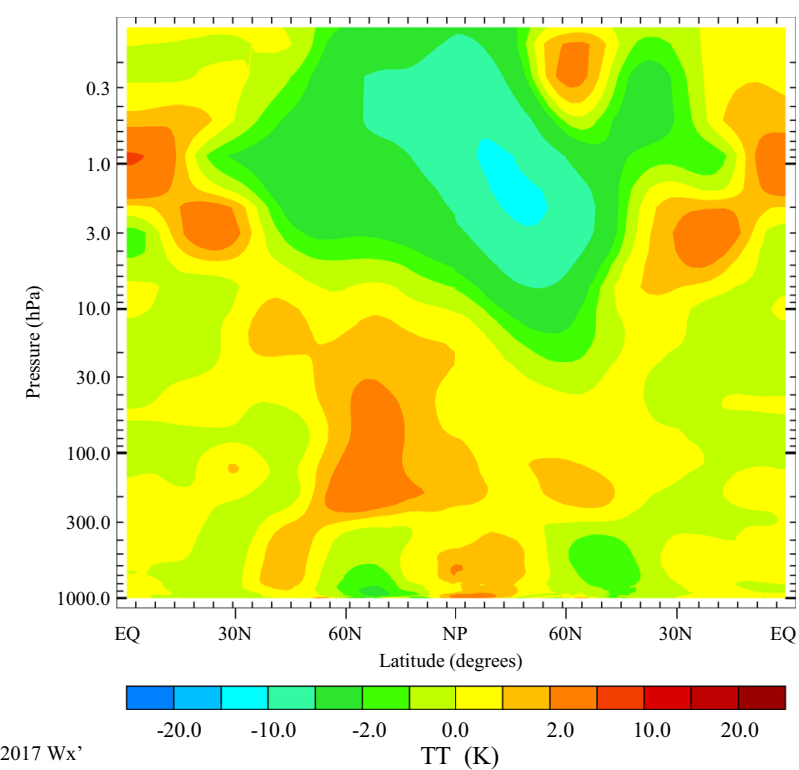

Fig. 3 Left: The difference between the seasonal mean temperature between scenario A1 and A0, averaged over longitudes, separately for Western (W) and Eastern half of the Northern Hemisphere for the winter season. Right: The difference between the seasonal mean tem- temperature changes in the high latitudes, but with strong regional variation from month to month where changes reached $-5 \mathrm{~K}$.

During the winter season, the aviation emissions lead to a small temperature decrease in the low latitudes' upper troposphere indicate (up to $-2 \mathrm{~K}$ ). The changes in the midlatitudes' troposphere vary, depending on region, from $-2 \mathrm{~K}$ (mainly over the Eastern $\mathrm{NH}$ ) up to $2 \mathrm{~K}$ (mostly over the Western NH), as can be seen on Fig. 3. In the mid-latitude UTLS region, the aviation emissions mainly cause small (up to $-2 \mathrm{~K}$ ) temperature increase. The changes due to aviation emissions in the high latitudes' lower troposphere indicate $\mathrm{a}-5 \mathrm{~K}$ decrease over the region between mid- and high latitudes but up to $5 \mathrm{~K}$ increase over the Arctic region. In the UTLS, we were able to observe up to $5 \mathrm{~K}$ temperature increase.

The analysis of the monthly regional changes shows pronounced temperature differences between scenarios, especially over the high latitudes. The largest differences between scenarios occurred over Russia, Europe, Baffin Bay, the Bering Sea and Central North America, with temperature variation from $-9 \mathrm{~K}$ up to $10 \mathrm{~K}$, from $-6 \mathrm{~K}$ to $0 \mathrm{~K}$, from $-9 \mathrm{~K}$ to $5 \mathrm{~K}$, from $-10 \mathrm{~K}$ to $5 \mathrm{~K}$ and from $-7 \mathrm{~K}$ up to $3 \mathrm{~K}$, respectively. Only over the central and eastern part of the USA, there was a constant increase in temperature in scenario A1, with the differences between scenarios of less than $4 \mathrm{~K}$. In the UTLS region, we noticed a small decrease

Average latitude bands for A1-A0_3x3_2006_DJF

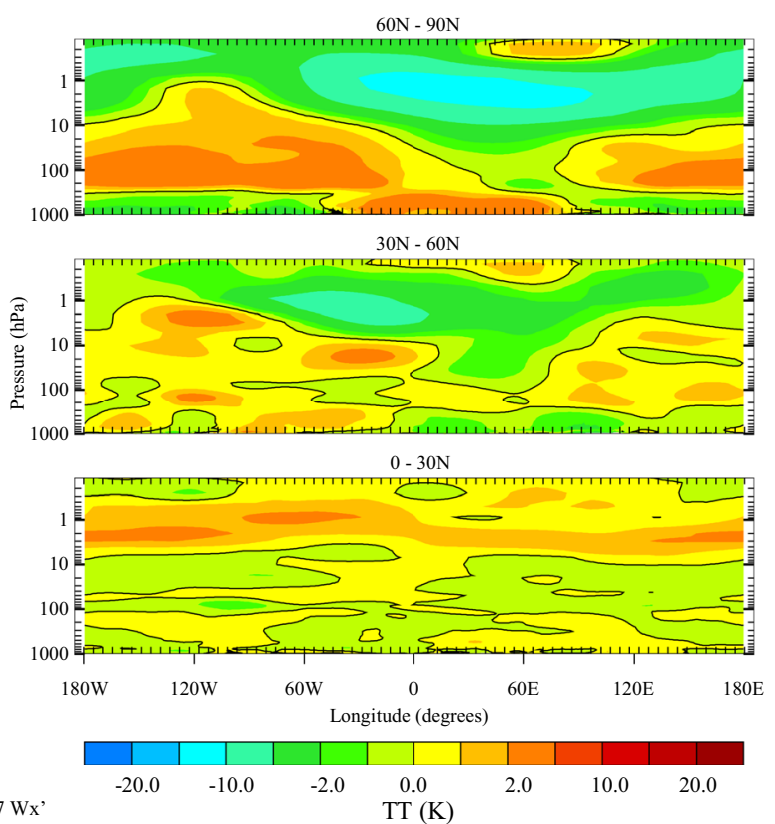

perature between scenario $\mathrm{A} 1$ and $\mathrm{A} 0$, averaged over latitudes for low $(0-30 \mathrm{~N})$, mid $(30-60 \mathrm{~N})$ and high $(60-90 \mathrm{~N})$ latitudes bands for the winter season 
$(-3 \mathrm{~K})$ over the Atlantic Ocean between $30^{\circ} \mathrm{N}$ and $45^{\circ} \mathrm{N}$. A similar tendency occurred over the Pacific Ocean for the same latitude range, but with stronger variation along the longitudes. The increase in the UTLS temperature occurred mostly over the Western US, Canada, the Labrador Sea and Greenland, with the highest difference of up to $5 \mathrm{~K}$. Also, a small temperature increase was noticed over the eastern part of Russia, where the differences between scenario A1 and A0 did not exceed $3 \mathrm{~K}$. Over Europe, monthly differences varied from $3 \mathrm{~K}$ to $-4 \mathrm{~K}$.

During the spring season, the analysis of changes between scenarios A1 and A0 also indicates a small (up to $-2 \mathrm{~K}$ ) temperature decrease in the low latitudes upper troposphere due to aviation emissions. In the mid-latitudes, the influence of aviation emissions on the troposphere temperature leads to substantial regional variation, mostly related to the ocean-land presence (please see Fig. 4, right panel). Over the region with land domination (except Eastern Europe), we noticed up to $5 \mathrm{~K}$ temperature increase in the troposphere. In contrast, for the region with ocean domination-scenario A1 shows up to $-5 \mathrm{~K}$ lower mean meridional temperature. That may be connected with the stronger aviation emissions in the lower and mid-troposphere over the land, because of the presence of airports, while over the oceans aviation emissions take place at cruising altitudes because of the small number of airports at isolated archipelagos. In the mid-latitudes UTLS region, the temperature changes due to

W \& E hemisperic average for A1-A0_3x3_2006_MAM

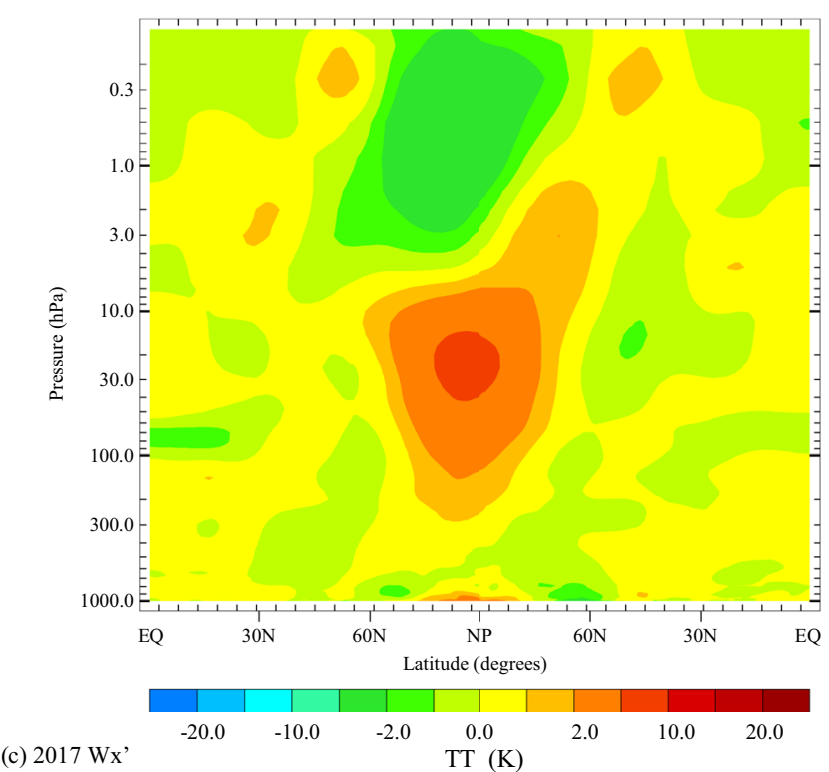

Fig. 4 Left: The difference between the seasonal mean of temperature between scenario A1 and A0, averaged over longitudes, separately for Western (W) and Eastern half of the Northern Hemisphere for the spring season. Right: The difference between the seasonal mean of aviation emissions were opposite to the trend we noticed in the troposphere and varies from $-2 \mathrm{~K}$ over the lands up to $2 \mathrm{~K}$ over the oceans. The mean zonal temperature difference for spring season shows the small west-east hemispheric contrast with the prevailing warming effects in the Eastern $\mathrm{NH}$ and cooling effect in the Western $\mathrm{NH}$ of the aviation emissions in the troposphere. Over the high latitudes, we noticed the same general trends in temperature changes as we did for winter months. The temperature increases (up to $2 \mathrm{~K})$ over the Arctic, but there is a small $(-2 \mathrm{~K})$ decrease around the Arctic between $60^{\circ} \mathrm{N}$ and $70^{\circ} \mathrm{N}$. In the high latitudes UTLS region, the aviation emissions scenario shows up to $5 \mathrm{~K}$ temperature increase (especially in the lower stratosphere).

For the summer, the decreasing trend in the low latitude upper troposphere temperature due to aviation emissions visible during the winter and spring seasons start to change, showing the regional upper troposphere temperature increase. The analysis of monthly zonal temperature means for low latitudes indicate month to month trend changing from temperature decrease to temperature increase in scenario A1. In the mid-latitudes troposphere, the seasonal mean temperature difference between scenarios was rather small and oscillated between $\pm 1 \mathrm{~K}$. The changes in the midlatitudes UTLS indicate a similar regional variation as in the troposphere, but with the opposite sign of changes (see Fig. 5, right middle panel). These regional changes follow

Average latitude bands for A1-A0_3x3_2006_MAM

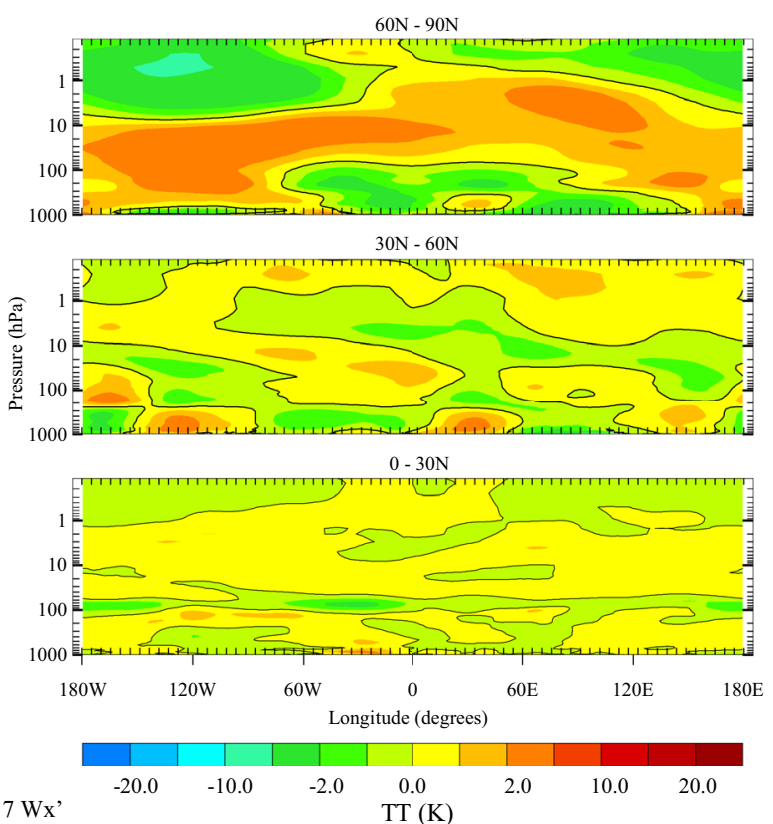

temperature between scenario $\mathrm{A} 1$ and $\mathrm{A} 0$, averaged over latitudes for low $(0-30 \mathrm{~N})$, mid $(30-60 \mathrm{~N})$ and high $(60-90 \mathrm{~N})$ latitudes bands for the spring season 
W \& E hemisperic average for A1-A0 3x3 2006 JJA

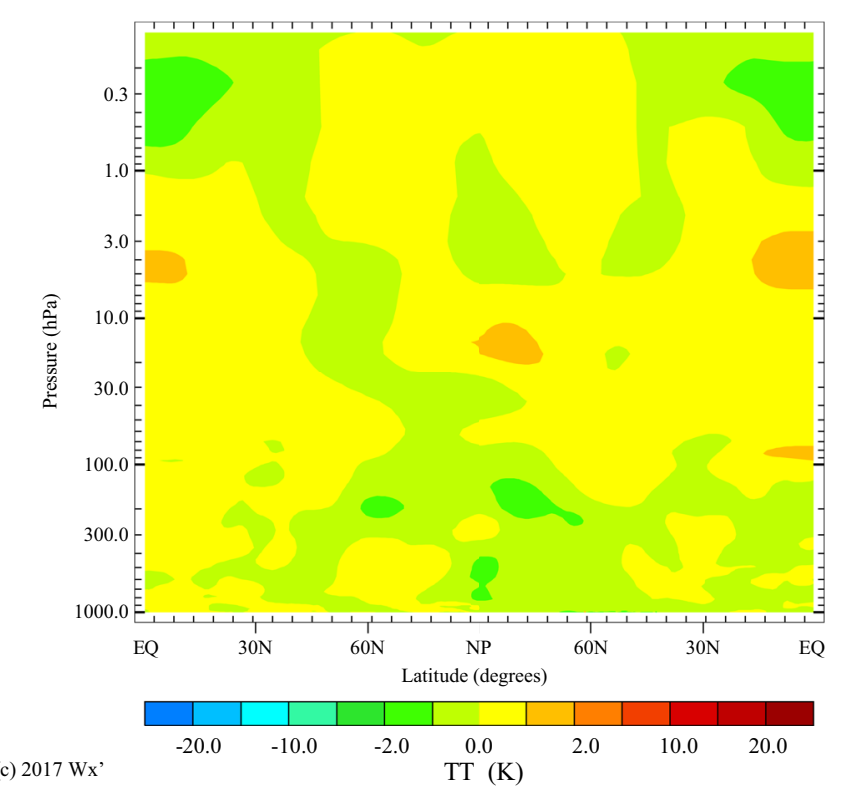

Fig. 5 Left: The difference between the seasonal means of temperature between scenario A1 and A0, averaged over longitudes, separately for Western (W) and Eastern half of the Northern Hemisphere the summer season. Right: The difference between the seasonal

the trend described for the spring season. In the high latitudes, we noticed a decreasing trend in temperature due to aviation emissions. The exception occurred between $30^{\circ} \mathrm{W}$ and $120^{\circ} \mathrm{W}$, over the northern part of Canada and Greenland, where we noticed up to $5 \mathrm{~K}$ increase.

During the autumn season, the direction of changes in the low latitudes upper troposphere indicates a $2 \mathrm{~K}$ increase in temperature due to aviation emissions. The changes in the troposphere and UTLS mean temperature over the midlatitudes have a robust regional variability, similar to the trend described for spring and summer season with a small spatial shift. The overall mean seasonal changes indicate a small $(1 \mathrm{~K})$ tropospheric temperature increase over the Western $\mathrm{NH}$ and a small $(-1 \mathrm{~K})$ temperature decrease over the Eastern NH. Over the high latitudes, the changes in the lower troposphere indicate a-2 K decrease over the Arctic with $1 \mathrm{~K}$ increase over Northern Canada and Scandinavia. The changes in the high latitude UTLS vary from $-2 \mathrm{~K}$ over the Siberia region up to $5 \mathrm{~K}$ over North Canada. The mean seasonal changes over the high latitudes UTLS during autumn indicate a $2 \mathrm{~K}$ increase in scenario $A 1$ (Fig. 6).

The mean annual changes between scenarios presented in Fig. 2 show no noticeable changes between scenarios. However, the analysis shows significant monthly and regional differences between scenarios A1 and A0. Although the most intense aviation emissions occur over the mid-latitudes,

\section{Average latitude bands for A1-A0_3x3_2006_JJA}

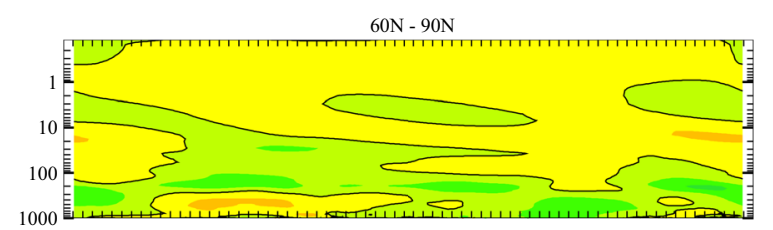

$30 \mathrm{~N}-60 \mathrm{~N}$

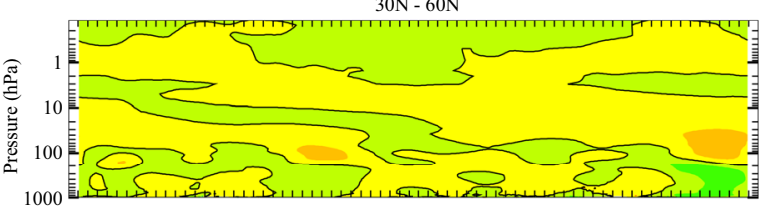

$0-30 \mathrm{~N}$

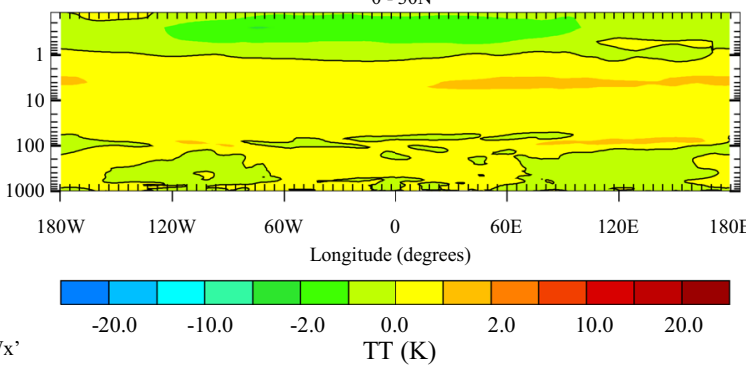

(c) $2017 \mathrm{Wx}$

means of temperature between scenario A1 and A0, averaged over latitudes for low $(0-30 \mathrm{~N})$, mid $(30-60 \mathrm{~N})$ and high $(60-90 \mathrm{~N})$ latitudes bands for the summer season

the most sensitive regions seem to be high and near high latitudes, where the changes vary in a range of $\pm 7 \mathrm{~K}$. The changes in the temperature over the mid-latitudes show a less strong response to aviation emissions, yet the changes strongly depend on the emission area. When aviation emissions were present in the whole troposphere, we observed the temperature increase in the low and middle troposphere but decrease in the UTLS region. On the one hand, when aviation emissions were limited only to cruise altitudes temperature in the UTLS increase while in the middle and low troposphere, we noticed a temperature decrease. The influence of aviation emissions on the tropical upper troposphere's temperature was the weakest, yet we still noticed some small changes.

\section{Changes in the jet stream propagation}

The analysis of annual means shows almost no differences between scenarios A1 and A0 for the zonal wind velocity and only small shifts in the meridional jet stream velocity over the North America mid-latitudes (Fig. 7). However, differences between scenarios in seasonal and monthly mean values show noticeable changes in the jet stream propagation.

The strongest influence of aircraft emissions on jet stream was noticed during the winter season, where 
W \& E hemisperic average for A1-A0_3x3_2006_SON

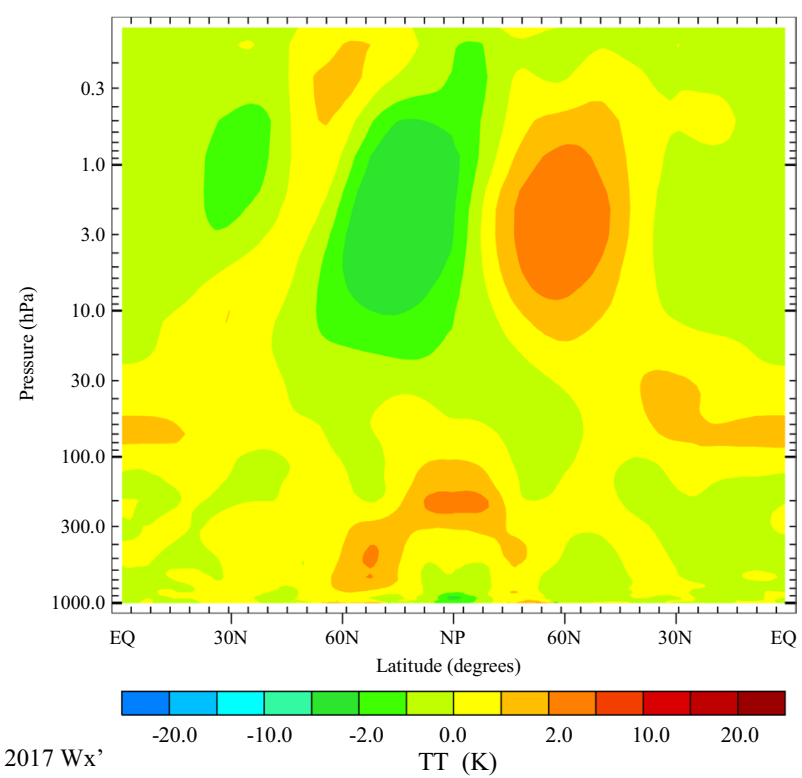

Fig. 6 Left: The difference between the seasonal means of temperature between scenario A1 and A0, averaged over longitudes, separately for Western (W) and Eastern half of the Northern Hemisphere for the autumn season. Right: The difference between the seasonal

W \& E hemisperic average for A1-A0_3x3_2006_YEAR

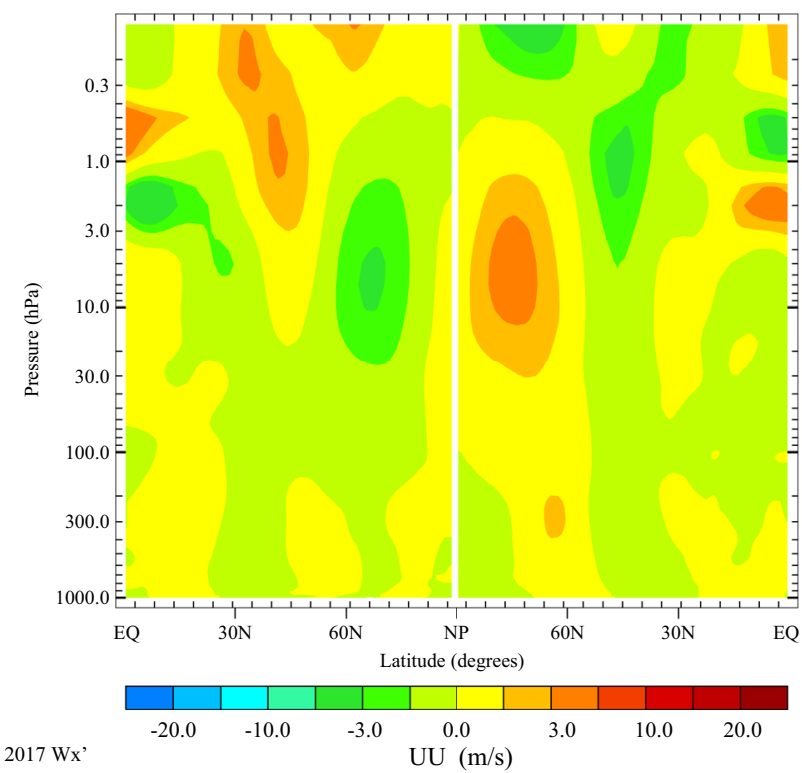

Fig. 7 Left: The difference between annual means of zonal wind velocity between scenario A1 and A0, averaged by longitudes, separately for Western (W) and Eastern half of the Northern Hemisphere.
Average latitude bands for A1-A0_3x3_2006_SON
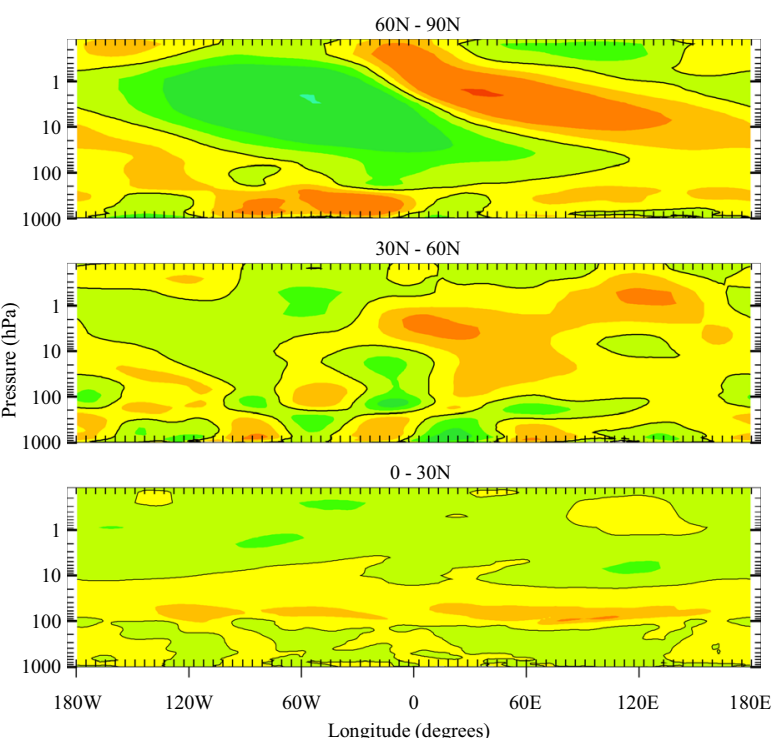

(c) $2017 \mathrm{Wx}$ '

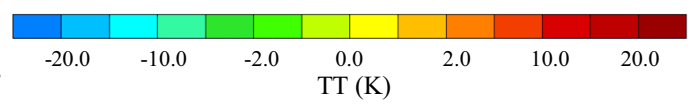

means of temperature between scenario $\mathrm{A} 1$ and $\mathrm{A} 0$, averaged over latitudes for low $(0-30 \mathrm{~N})$, mid $(30-60 \mathrm{~N})$ and high $(60-90 \mathrm{~N})$ latitudes bands for the autumn season

Average latitude bands for A1-A0_3 3 3 2006_YEAR
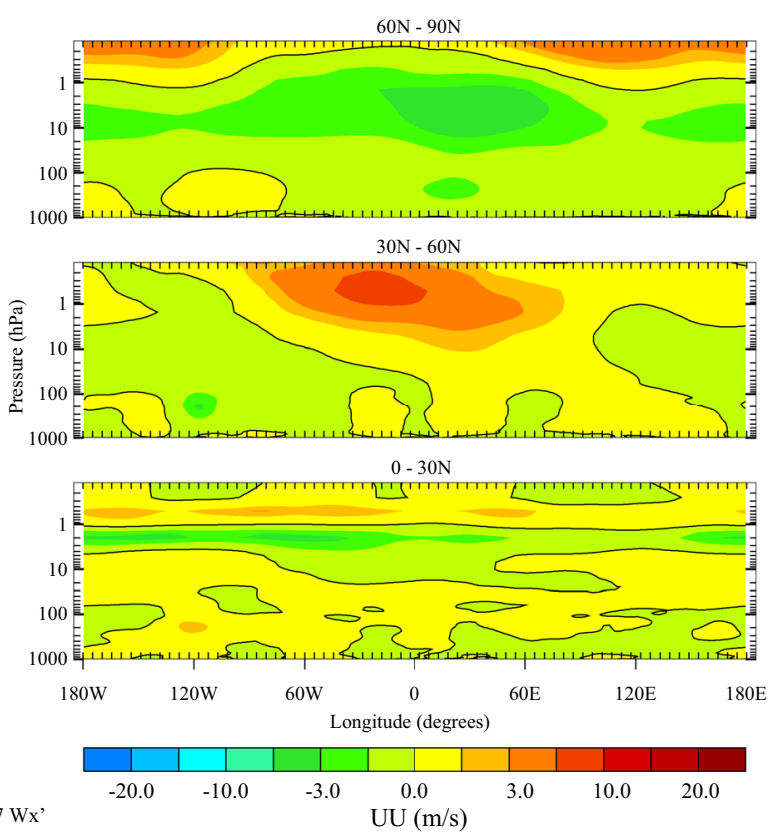

(c) $2017 \mathrm{Wx}$ '

Right: The difference between annual means of meridional wind velocity between scenario A1 and A0, averaged over latitudes for low $(0-30 \mathrm{~N})$, mid $(30-60 \mathrm{~N})$ and high $(60-90 \mathrm{~N})$ latitudes bands 
aviation caused an increase in zonal wind velocity in the UTLS region over the high and low latitudes and a decrease in mid-latitudes, indicating the separation of the STJ and EDJ. The poleward shift of the polar jet stream and equatorward shift of the STJ was observed mostly over the Western Hemisphere. The changes over the Eastern Hemisphere in the seasonal wind speed analysis are less visible. Analysis of the regional changes in the jet stream propagation shows that the largest differences between scenarios occurred over Northern America, the Atlantic Ocean, East Asia and the Pacific Ocean. In the scenario with aviation emissions, the jet stream has a tendency to split into two streams and propagate on both sides of the Rocky Mountains, travelling more often over Northern Canada and more often over the southern part of the USA. Those stronger tendencies to propagate along the Rocky Mountains can be seen in changes in the meridional wind velocity, shown in Fig. 8. Both the EDJ and STJ jets stay separated over the Atlantic Ocean. The tendency of the jet stream to split over North America results in poleward (EDJ) and equatorward (STJ) shifts we noticed in the seasonal mean of the wind velocity in the UTLS region. Also, we noticed a tendency of jet stream superposition over Asia, which cause a decrease in EDJ occurrence over the Eastern Siberia and wind velocity increase over East Asia

W \& E hemisperic average for A1-A0 3x3 2006 DJF

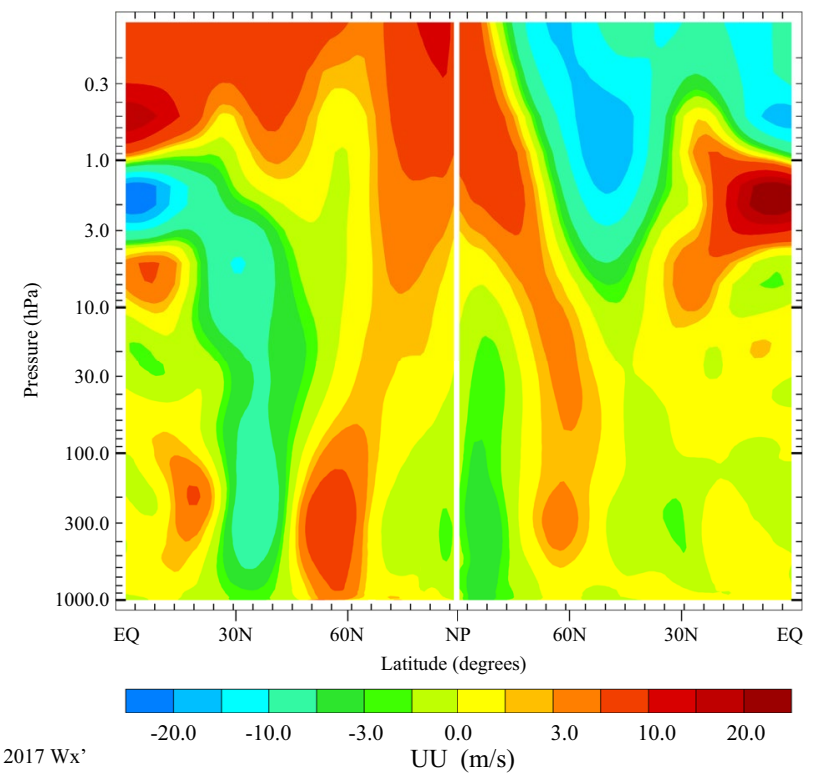

Fig. 8 Left: The difference between and seasonal means of zonal wind velocity between scenario $\mathrm{A} 1$ and $\mathrm{A} 0$, averaged over longitudes, separately for Western (W) and Eastern half of the Northern Hemisphere for the winter season. Right: The difference between seasonal
(China). The tendency for January is shown as an example in Fig. 9.

The analysis of differences in the jet core velocity between $\mathrm{A} 1$ and $\mathrm{A} 0$ scenarios shows small, not noticeable changes in the seasonal mean of the jet core velocity. However, the regional differences between scenarios can reach up to $-10 \mathrm{~m} / \mathrm{s}$. The largest difference occurred over the Pacific Ocean in January, when the monthly mean of the jet core velocity in scenario A1 was around $66 \mathrm{~m} / \mathrm{s}$ while in scenario A0 it was $77 \mathrm{~m} / \mathrm{s}$. During the spring season, the changes between scenarios were less visible as compared to the winter season. The direction of changes in the spring season did not follow the winter trend. The jet streams in the scenario with aviation emissions show a small equatorward shift with a stronger and more stable subtropical jet. The changes in the jet stream propagation vary between scenarios on a month to month time scale. Still, the mean seasonal trend shows that stronger changes occurred over the Western Northern Hemisphere (Fig. 10).

The regional changes in the jet streams propagation due to aviation emissions mostly affected the Pacific and Atlantic Oceans. Analysis of the monthly means of wind velocity field indicates that in scenario A1 the jet stream tends to split over the East Pacific, where EDJ propagate poleward toward Alaska and Canada, and STJ propagate equatorward toward Mexico. This tendency follows the trend from the winter

Average latitude bands for A1-A0_3x3_2006_DJF

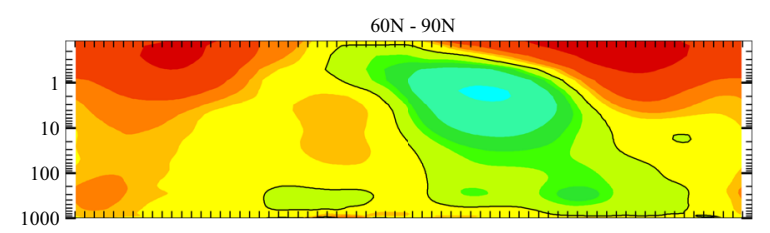

$30 \mathrm{~N}-60 \mathrm{~N}$

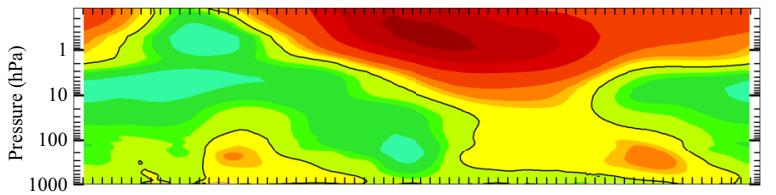

$0-30 \mathrm{~N}$

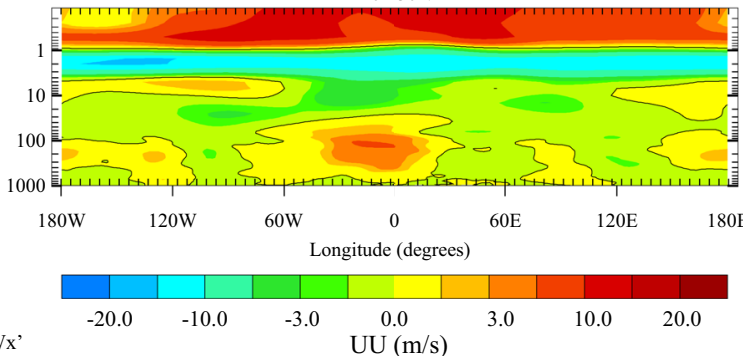

(c) $2017 \mathrm{Wx}$

means of meridional wind velocity between scenario A1 and A0, averaged over latitudes for low $(0-30 \mathrm{~N})$, mid $(30-60 \mathrm{~N})$ and high (60-90 N) latitudes bands for the winter season 


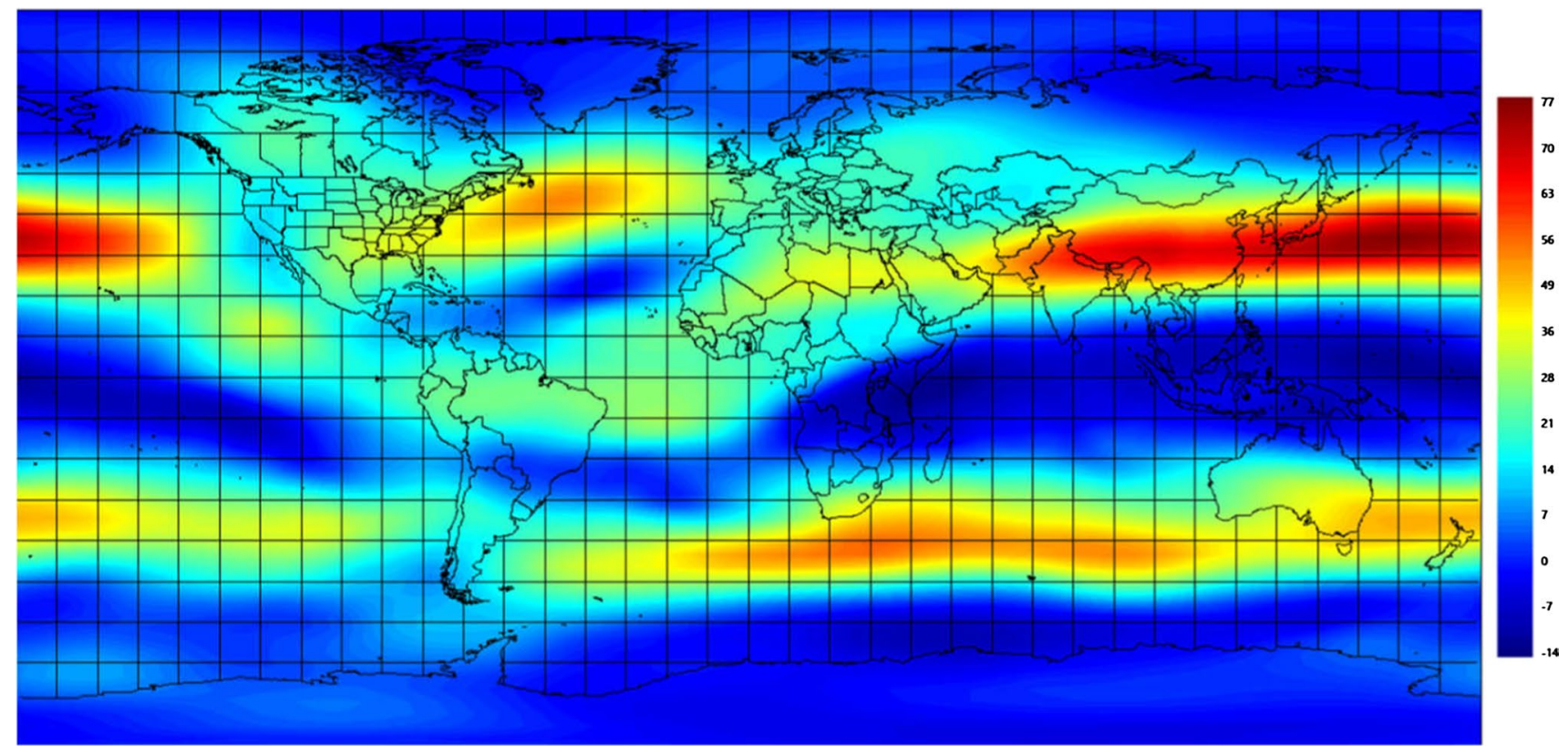

Fig. 9 Monthly mean wind velocity at $250 \mathrm{hPa}$ in knots for scenario A1 (top panel) and scenario A0 middle panel). The bottom panel shows a difference between monthly mean wind velocity between scenarios A1 and A0 at $250 \mathrm{hPa}$ in knots. 1 knot is equal to $0.514 \mathrm{~m} / \mathrm{s}$

W \& E hemisperic average for A1-A0_3x3_2006_MAM

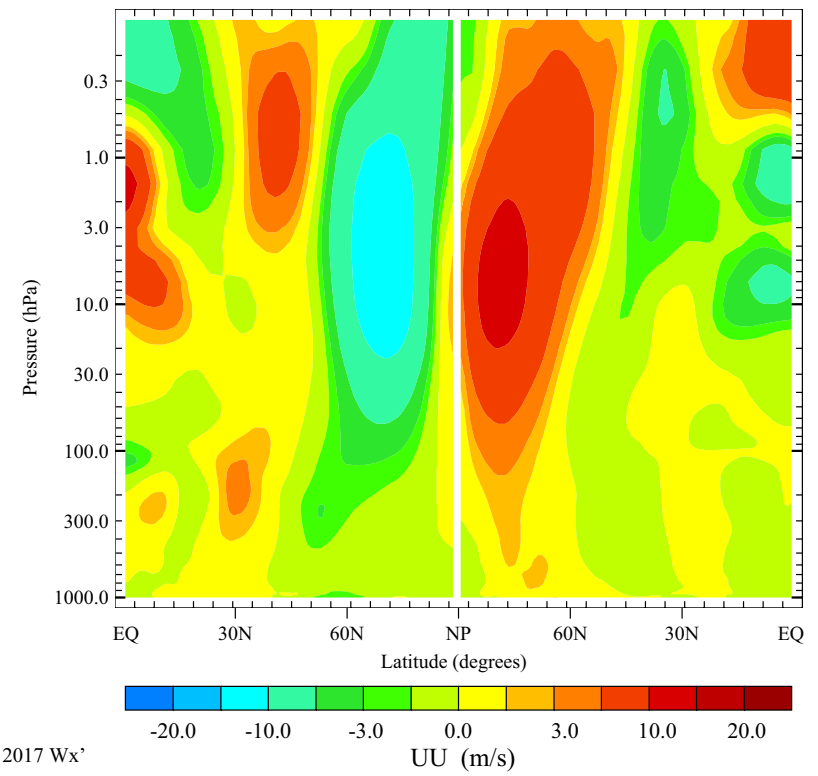

Fig. 10 Left: The difference between seasonal means of zonal wind velocity between scenario A1 and A0, averaged over longitudes, separately for Western (W) and Eastern half of the Northern Hemisphere for the spring season. Right: The difference between seasonal means
Average latitude bands for A1-A0_3x3_2006_MAM
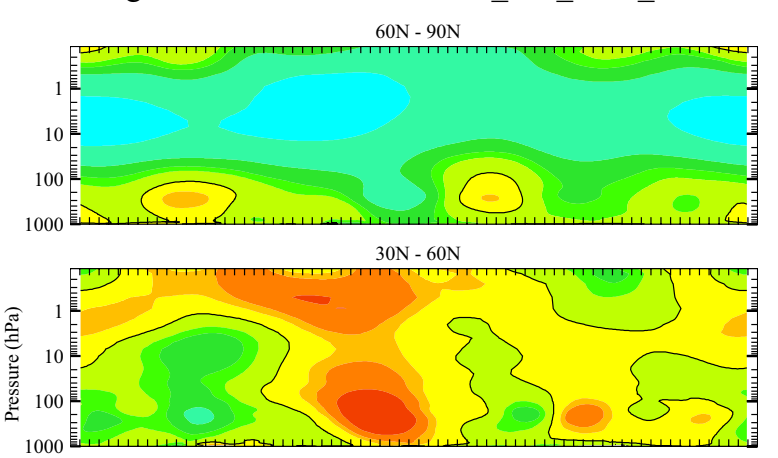

1000

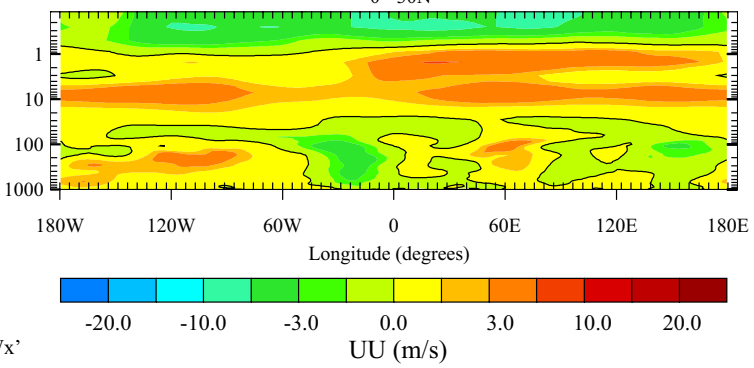

(c) $2017 \mathrm{Wx}$ '

of meridional wind velocity between scenario A1 and A0, averaged over latitudes for low $(0-30 \mathrm{~N})$, mid $(30-60 \mathrm{~N})$ and high $(60-90 \mathrm{~N})$ latitudes bands for the spring season 
W \& E hemisperic average for A1-A0 3x3 2006 JJA

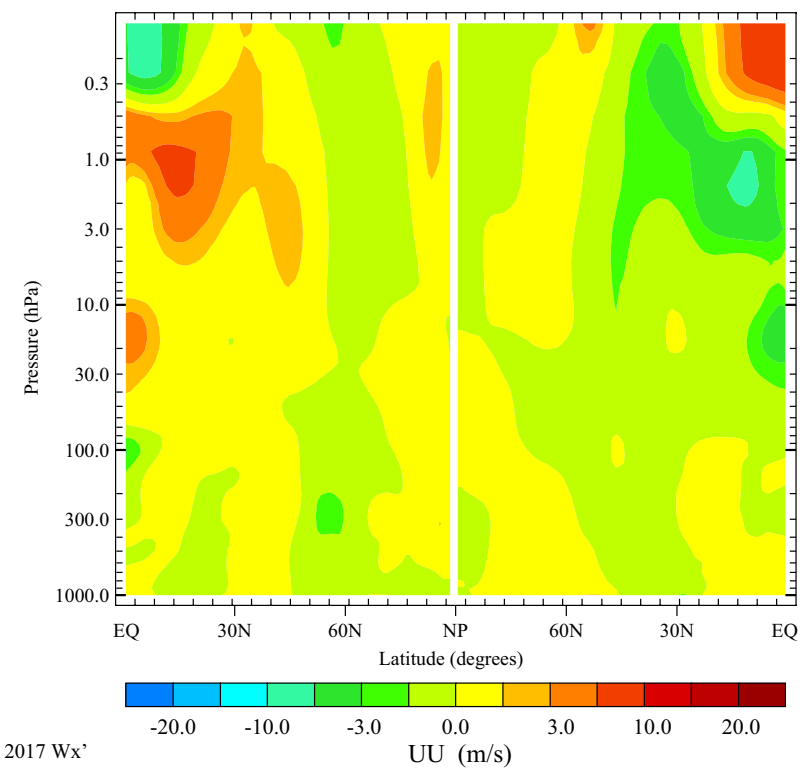

Fig. 11 Left: The difference between seasonal means of zonal wind velocity between scenario A1 and A0, averaged over longitudes, separately for Western (W) and Eastern half of the Northern Hemisphere for the summer season. Right: The difference between seasonal

season. In scenario A0, this tendency is much weaker and appears at the end of the spring season. On the other hand, in the scenario without aviation emissions, we noticed a strong tendency to form the North Atlantic Subtropical High that split the jet flow into two streams. The blocking pattern of the Bermuda-Azores high is not visible in the results for the scenario A1.

The smallest changes in the jet stream propagation due to the aviation emissions were found during the summer season (Fig. 11). Analysis of the monthly zonal means of the wind velocity has shown the small variation in the zonal jet stream flow between scenarios. Small shifts in the jet stream propagation, visible in monthly means of the zonal wind speed in the upper troposphere, show no particular trend in the jet stream modification between June and August for A1 and A0 scenarios. For the meridional wind velocity, we noticed meander-like structures in the jet stream propagation over the mid-latitudes. The monthly means show that in scenario A1 the jet stream tends to wobble more often over North America. In contrast, in scenario A0, the meanders are more frequent over Asia and the Pacific Ocean. The changes over North America were connected to the stronger trend of the jet stream split over the East Pacific Ocean that we noticed in scenario A1 from the winter season. The differences over Asia and the West Pacific Ocean were due to an increase in the tendency to jet stream split over Asia in the scenario with aviation emissions. This tendency results in more frequent
Average latitude bands for A1-A0_3x3_2006_JJA
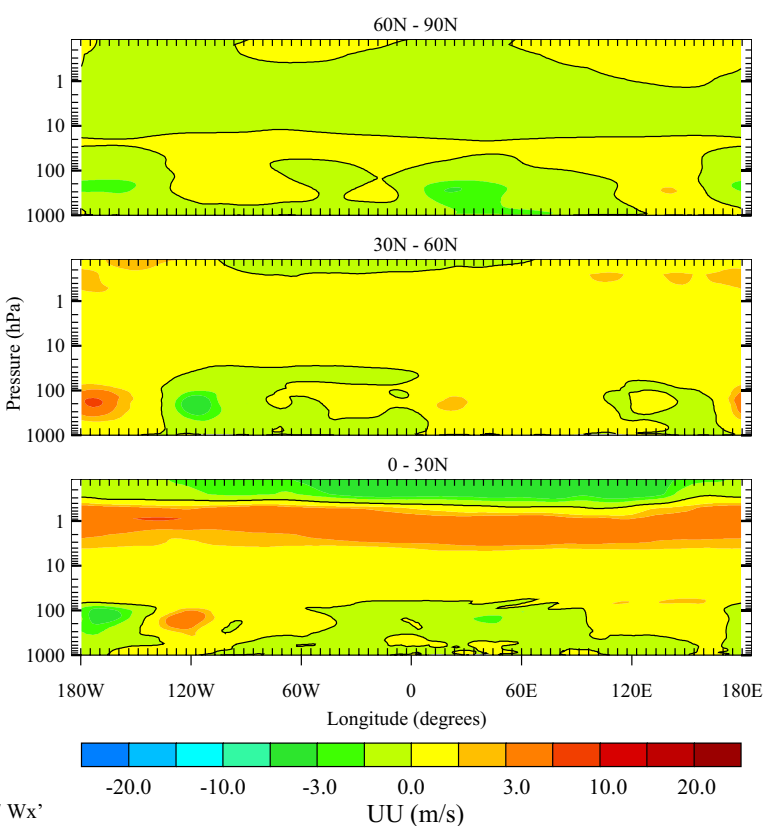

means of meridional wind velocity between scenario A1 and A0, averaged over latitudes for low $(0-30 \mathrm{~N})$, mid $(30-60 \mathrm{~N})$ and high $(60-90 \mathrm{~N})$ latitudes bands for the summer season

EDJ occurrence over the high latitudes and equatorward shift of the STJ over the West Pacific Ocean during the summer season.

The analysis of the differences between wind fields for the autumn season indicates a poleward shift of the EDJ and STJ in the scenario with aviation emissions, as presented in Fig. 12. Both scenarios show the tendency to jet stream split over the East Pacific Ocean, but in the scenario A0, this tendency is more noticeable. The differences in meridional flow indicate a significant change in the jet stream propagation, especially over Asia. The analysis of the wind velocity in the UTLS region shows that in both scenarios, the jet streams tend to wobble with similar intensity. There was no noticeable tendency in changes in jet stream meandering between scenarios A1 and A0. The strongest influence of aviation emissions was observed over the Pacific Ocean, Atlantic Ocean and Europe. In the scenario with aviation emissions, the jet stream shows a poleward shift over the Pacific Ocean with a small difference in the mean jet core velocity. On the other hand, over the western part of the Atlantic Ocean, we noticed a significant decrease in jet stream strength and equatorward shift of the jet stream flow over Europe that leads to the increase in the zonal wind velocity over Central and South Europe.

In summary, there is a noticeable month to month and season to season variation in the jet streams propagation between scenarios A1 and A0. The most significant 
W \& E hemisperic average for A1-A0 3x3 2006 SON

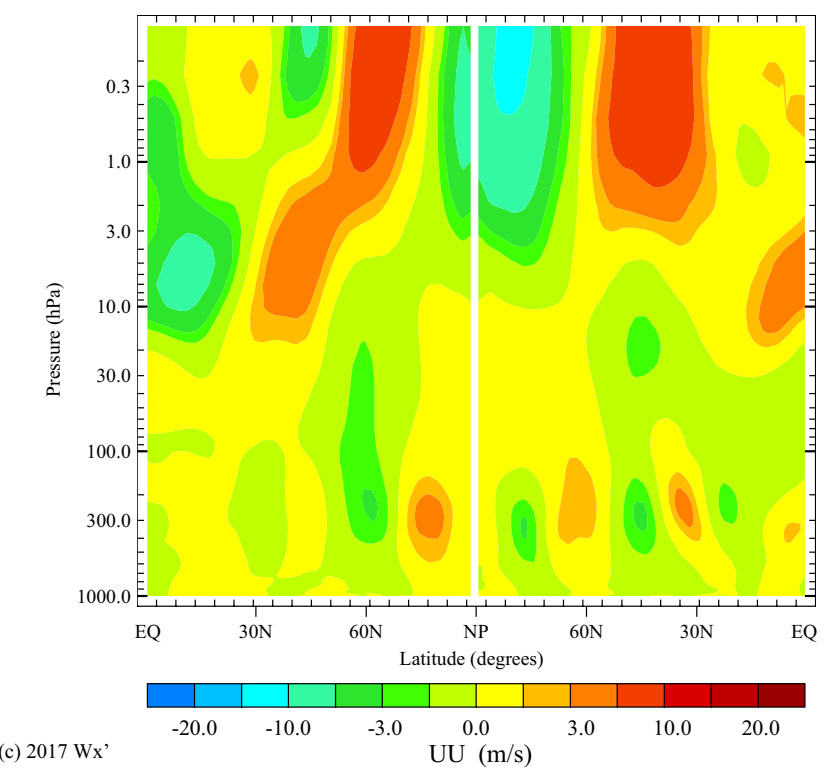

Fig. 12 Left: The difference between seasonal means of zonal wind velocity between scenario A1 and A0, averaged over longitudes, separately for Western (W) and Eastern half of the Northern Hemisphere for the autumn season. Right: The difference between seasonal means

difference occurred during the winter season and the smallest in summer. There is no regular trend in the jet stream shifts between scenarios. During the colder time of the year, the EDJ tends to shift poleward while during the spring season we noticed an equatorward shift in scenario A1. The analysis of the jet core monthly mean velocity shows no difference between scenarios except for the winter season, when the jet streams in scenario A1 seems to be slower as compared to the results for the A0 scenario. Regional changes in the jet stream propagation due to aviation emissions are mainly visible over the Pacific and Atlantic Oceans, where jet streams tend to be more stable, most likely due to the uniform surface. The most noticeable difference between scenarios is the stronger tendency of the jet stream split in scenario A1, especially over the East Pacific Ocean.

\section{Summary and conclusions}

Changes in the troposphere and the UTLS region temperature due to aviation emissions indicate around $2 \mathrm{~K}$ temperature decrease in the tropical upper troposphere region during the winter season, while in the UTLS region over high latitudes we noticed up to $5 \mathrm{~K}$ temperature increase. The analysis of changes in the tropopause temperature, presented by Hu and Vallis (2019) for the years 1979-2017 shows that the standard deviation of the mean annual temperature at
Average latitude bands for A1-A0_3x3_2006_SON
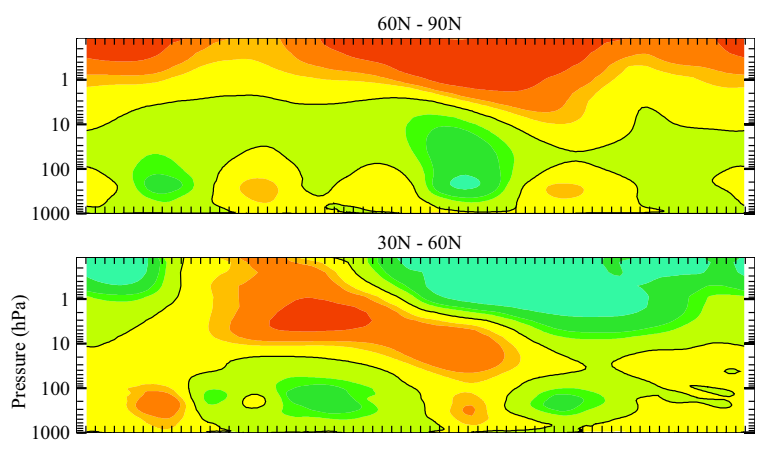

$0-30 \mathrm{~N}$

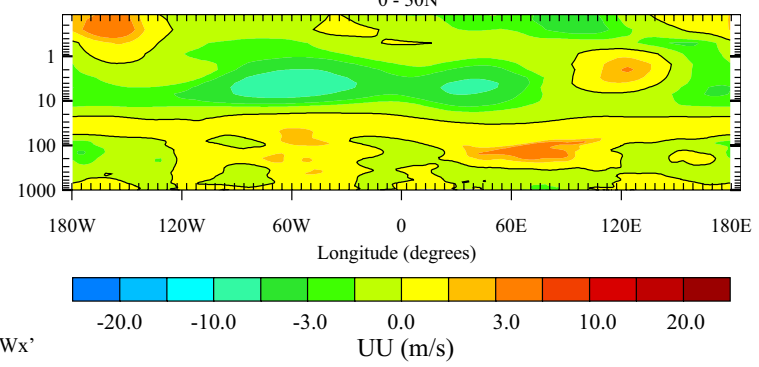

(c) $2017 \mathrm{Wx}$ '

of meridional wind velocity between scenario A1 and A0, averaged over latitudes for low $(0-30 \mathrm{~N})$, mid $(30-60 \mathrm{~N})$ and high $(60-90 \mathrm{~N})$ latitudes bands for the autumn season

the tropopause is $1.5 \mathrm{~K}$ and $1.0 \mathrm{~K}$, for the low and high latitudes, respectively. We can assume that changes in the tropical tropopause exceed $1 \sigma$ of the mean annual climatological tropopause temperature variation, and for the latitudes the changes due to aviation emissions exceed $2 \sigma$. It would indicate significant changes in the UTLS temperature, especially over the high latitudes.

The general propagation of the jet stream in scenarios $\mathrm{A} 1$ and $\mathrm{A} 0$ was in agreement with the results presented by Christenson et al. (2017), Koch et al. (2006), Kuang et al. (2014) or Pena-Ortic et al. (2013). Also, there were regional differences, especially over North America and North Asia, where scenario A1 shows better agreement with jet stream climatological studies than was expected. The preliminary results of the presented one-year case study show that aviation emissions lead to significant changes in jet stream propagation. Analysis of changes in the jet streams propagation indicates that the aviation emissions lead to more polar and subtropical jet splits than in the scenario without aviation emissions, especially during winter. We noticed a poleward EDJ shift during the colder part of the year that may be caused by changes in the UTLS temperature described in the previous paragraph. During the winter, the warming of the high latitudes UTLS is stronger than the cooling in the tropical upper troposphere that leads to the poleward shift of the jet streams over the Northern Hemisphere in scenario A1 during the winter season. The poleward shift of the jet 
streams in the autumn season was mostly connected with warming over the high latitudes rather than changes in the TTL. There were no significant changes in the jet stream velocity except in winter, when the mean seasonal jet core velocity in scenario A1 was about $10 \mathrm{~m} / \mathrm{s}$ slower than in scenario A0. There was no strong constant tendency of the jet stream more frequent wobble flow, yet there were significant regional differences in the jet streams propagation. The most noticeable changes were observed over the Eastern Pacific, Eastern Atlantic and North-East Asia. Over the Northern Pacific, we observed a significant difference in jet streams split what leads to changes in the North Pacific High (NHP) development. In scenario A1, the persistent high pressure system was much stronger in the spring season and weaker in autumn than in scenario A0. These changes may have a significant influence on drought season, especially over California. Another important change in mid-latitudes was the impact of aviation emissions on Bermuda-Azores High during the spring season, which was caused by changes in the jet stream propagation over the North and Subtropical Atlantic. Over Asia (Siberia), we observed stronger and more poleward EDJ in scenario A0.

Modelling results have shown that aviation emissions alone may have a significant influence on the jet stream propagation that leads to the conclusion that aviation emissions may have a significant influence on the climate. At this point, it is essential to highlight that the presented study covered the early research results, based only on one year of the simulation, focusing on the question "if aviation emissions may influence the jet stream propagation". The future results will be focused on climatological aspects of changes in the jet stream due to increasing aviation traffic.

Acknowledgements MK was supported by the National Science Centre Poland, Grant No. UMO 2013/11/N/ST10/00330 and Grant No. 2016/23/B/ST10/03192. JWK was supported by Transport Canada, Contract No: T8497-120001/01/TOR.

\section{Compliance with ethical standards}

Conflict of interest On behalf of all authors, the corresponding author states that there is no conflict of interest.

Open Access This article is licensed under a Creative Commons Attribution 4.0 International License, which permits use, sharing, adaptation, distribution and reproduction in any medium or format, as long as you give appropriate credit to the original author(s) and the source, provide a link to the Creative Commons licence, and indicate if changes were made. The images or other third party material in this article are included in the article's Creative Commons licence, unless indicated otherwise in a credit line to the material. If material is not included in the article's Creative Commons licence and your intended use is not permitted by statutory regulation or exceeds the permitted use, you will need to obtain permission directly from the copyright holder. To view a copy of this licence, visit http://creativecommons.org/licenses/by/4.0/.

\section{References}

Barnes EA, Polvani L (2013) Response of the Midlatitude jets, and of their variability, to increased greenhouse gases in the CMIP5 models. J Clim 26:7117-7135. https://doi.org/10.1175/JCLID-12-00536.1

Barnes EA, Screen JA (2015) The impact of Arctic warming on the midlatitude jet-stream: Can it? Has it? Will it? Wiley Interdiscip Rev Clim Change 6:277-286. https://doi.org/10.1002/wcc.337

Barnes EA, Simpson IR (2017) Seasonal sensitivity of the Northern Hemisphere jet streams to arctic temperatures on subseasonal time scales. J Clim 30:10117-10137. https://doi.org/10.1175/ JCLI-D-17-0299.1

Brasseur GP (coordinating lead author) et al (2008) Aviation climate change research initiative: a report on the way forward based on the review of research gaps and priorities, Federal Aviation Administration, avaliable from: https://www.faa.gov/about/office org/headquarters_offices/apl/research/science_integrated_model ing/accri/media/ACCRI_Report_final.pdf. Accessed 22 May 2019

Christenson CE, Martin JE, Handlos ZJ (2017) A Synoptic climatology of Northern Hemisphere, cold season polar and subtropical jet superposition events. J Clim 30:7231-7246. https://doi. org/10.1175/JCLI-D-16-0565.1

Cohen J, Screen JA, Furtado JC et al (2014) Recent arctic amplification and extreme mid-latitude weather. Nat Geosci 7:627-637. https:// doi.org/10.1038/ngeo2234

de Grandpré J, Beagley SR, Fomichev VI et al (2000) Ozone climatology using interactive chemistry: results from the Canadian middle atmosphere model. J Geophys Res Atmos 105:26475-26491. https ://doi.org/10.1029/2000JD900427

Forster PMD, Shine KP (1997) Radiative forcing and temperature trends from stratospheric ozone changes. J Geophys Res 102:10841. https://doi.org/10.1029/96JD03510

Frömming C, Ponater M, Dahlmann K et al (2012) Aviation-induced radiative forcing and surface temperature change in dependency of the emission altitude: emission altitude and aviation impact. $\mathbf{J}$ Geophys Res Atmos. https://doi.org/10.1029/2012JD018204

Garfinkel CI, Hartmann DL (2010) Influence of the quasi-biennial oscillation on the North Pacific and El Niño teleconnections. J Geophys Res Atmos. https://doi.org/10.1029/2010JD014181

Gettelman A, Hoor P, Pan LL et al (2011) The extratropical upper troposphere and lower stratosphere. Rev Geophys 49:RG3003. https://doi.org/10.1029/2011RG000355

Grandpré J, Ménard R, Rochon YJ et al (2009) Radiative impact of ozone on temperature predictability in a coupled chemistrydynamics data assimilation system. Mon Wea Rev 137:679-692. https://doi.org/10.1175/2008MWR2572.1

Grewe V, Dameris M, Fichter C, Lee DS (2002) Impact of aircraft NOx emissions. part 2: effects of lowering the flight altitude. Meteorol Z 11:197-205. https://doi.org/10.1127/0941-2948/2002/0011-0197

Haigh JD, Blackburn M, Day R (2005) The response of tropospheric circulation to perturbations in lower-stratospheric temperature. $\mathrm{J}$ Clim 18:3672-3685. https://doi.org/10.1175/JCLI3472.1

Hall R, Erdélyi R, Hanna E et al (2015) Drivers of North Atlantic polar front jet stream variability. Int J Climatol 35:1697-1720. https:// doi.org/10.1002/joc.4121

Hegglin MI, Gettelman A, Hoor P et al (2010) Multimodel assessment of the upper troposphere and lower stratosphere: extratropics. J Geophys Res 115:D00M09. https://doi.org/10.1029/2010JD0138 84

Holton JR, Haynes PH, McIntyre ME et al (1995) Stratospheretroposphere exchange. Rev Geophys 33:403-439. https://doi. org/10.1029/95RG02097 
Hu S, Vallis GK (2019) Meridional structure and future changes of tropopause height and temperature. Q J R Meteorol Soc 145:2698-2717. https://doi.org/10.1002/qj.3587

IPCC AR5, Eds 2014 Climate change 2013-The physical science basis: working group I contribution to the fifth assessment report of the intergovernmental panel on climate change Cambridge University Press Cambridge

Jacobson MZ, Wilkerson JT, Balasubramanian S et al (2012) The effects of rerouting aircraft around the arctic circle on arctic and global climate. Clim Change 115:709-724. https://doi. org/10.1007/s10584-012-0462-0

Jensen EJ, Toon OB, Selkirk HB et al (1996) On the formation and persistence of subvisible cirrus clouds near the tropical tropopause. J Geophys Res Atmos 101:21361-21375. https://doi. org/10.1029/95JD03575

Kaminski JW, Neary L, Struzewska J et al (2008) GEM-AQ, an online global multiscale chemical weather modelling system: model description and evaluation of gas phase chemistry processes. Atmos Chem Phys 8:3255-3281. https://doi.org/10.5194/ acp-8-3255-2008

Kim BY, Fleming GG, Lee JJ et al (2007) System for assessing aviation's global emissions (SAGE), part 1: model description and inventory results. Transp Res Part D Transp Environ 12:325-346. https://doi.org/10.1016/j.trd.2007.03.007

Koch P, Wernli H, Davies HC (2006) An event-based jet-stream climatology and typology. Int J Climatol 26:283-301. https://doi. org/10.1002/joc.1255

Kuang X, Zhang Y, Huang Y, Huang D (2014) Spatial differences in seasonal variation of the upper-tropospheric jet stream in the Northern Hemisphere and its thermal dynamic mechanism. Theor Appl Climatol 117:103-112. https://doi.org/10.1007/s0070 4-013-0994-X

Lamarque J-F, Emmons LK, Hess PG et al (2012) CAM-chem: description and evaluation of interactive atmospheric chemistry in the community earth system model. Geosci Model Dev 5:369-411. https://doi.org/10.5194/gmd-5-369-2012

Lee DS, Fahey DW, Forster PM et al (2009) Aviation and global climate change in the twentyfirst century. Atmos Environ 43:3520 3537. https://doi.org/10.1016/j.atmosenv.2009.04.024

Lee DS, Pitari G, Grewe V et al (2010) Transport impacts on atmosphere and climate: aviation. Atmos Environ 44:4678-4734. https ://doi.org/10.1016/j.atmosenv.2009.06.005

Linz M, Chen G, Hu Z (2018) Large-scale atmospheric control on nongaussian tails of midlatitude temperature distributions. Geophys Res Lett 45:9141-9149. https://doi.org/10.1029/2018GL079324

Lund MT, Aamaas B, Berntsen T et al (2017) Emission metrics for quantifying regional climate impacts of aviation. Earth Syst Dynam 8:547-563. https://doi.org/10.5194/esd-8-547-2017

Lupu A, Semeniuk K, Kaminski JW, McConnell JC (2013) GEM-AC: a stratospheric-tropospheric global and regional model for air quality and climate change-evaluation of gas-phase properties. In: Bernath PF (ed) The atmospheric chemistry experiment ACE at 10: a solar occultation anthology. A. Deepak Publishing, Hampton, Virginia, USA, pp 285-293

Mamun A, Semeniuk K, Kaminski JW, McConnell JC (2013) Evaluation of stratospheric temperature and water vapor from GEM using ACE-FTS and MLS measurements. In: Bernath PF (ed) The atmospheric chemistry experiment ACE at 10: A solar occultation anthology. A. Deepak Publishing, Hampton, Virginia, U.S.A, pp 295-302

Melamed-Turkish K, Taylor PA, Liu J (2018) Upper-level winds over eastern North America: a regional jet stream climatology. Int J Climatol 38:4740-4757. https://doi.org/10.1002/joc.5693
Olsen SC, Brasseur GP, Wuebbles DJ et al (2013a) Comparison of model estimates of the effects of aviation emissions on atmospheric ozone and methane. Geophys Res Lett. https://doi. org/10.1002/2013GL057660

Olsen SC, Wuebbles DJ, Owen B (2013b) Comparison of global 3-D aviation emissions datasets. Atmos Chem Phys 13:429-441. https ://doi.org/10.5194/acp-13-429-2013

Pena-Ortiz C, Gallego D, Ribera P et al (2013) Observed trends in the global jet stream characteristics during the second half of the 20th century. J Geophys Res Atmos 118:2702-2713. https://doi. org/10.1002/jgrd.50305

Penner JE (1999) Aviation and the global atmosphere: a special report of the intergovernmental panel on climate change. Cambridge University Press

Rikus L (2018) A simple climatology of westerly jet streams in global reanalysis datasets part 1: mid-latitude upper tropospheric jets. Clim Dyn 50:2285-2310. https://doi.org/10.1007/s0038 2-015-2560-y

Shepherd TG (2007) Transport in the middle atmosphere. J Meteorol Soc Jpn Ser II 85B:165-191. https://doi.org/10.2151/jmsj.85B.165

Shepherd TG (2002) Issues in stratosphere-troposphere coupling. J Meteorol Soc Jpn Ser II 80:769-792. https://doi.org/10.2151/ jmsj. 80.769

Simpson IR, Blackburn M, Haigh JD (2012) A mechanism for the effect of tropospheric jet structure on the annular mode-like response to stratospheric forcing. J Atmos Sci 69:2152-2170. https://doi.org/10.1175/JAS-D-11-0188.1

Skowron A, Lee DS, De León RR (2015) Variation of radiative forcings and global warming potentials from regional aviation $\mathrm{NOx}$ emissions. Atmos Environ 104:69-78. https://doi.org/10.1016/j. atmosenv.2014.12.043

Søvde OA, Matthes S, Skowron A et al (2014) Aircraft emission mitigation by changing route altitude: a multi-model estimate of aircraft NOx emission impact on $\mathrm{O} 3$ photochemistry. Atmos Environ 95:468-479. https://doi.org/10.1016/j.atmosenv.2014.06.049

Strong C, Davis RE (2007) Winter jet stream trends over the Northern Hemisphere. Q J R Meteorol Soc 133:2109-2115. https://doi. org/10.1002/qj.171

Sun L, Chen G, Lu J (2013) Sensitivities and mechanisms of the zonal mean atmospheric circulation response to tropical warming. J Atmos Sci 70:2487-2504. https://doi.org/10.1175/ JAS-D-12-0298.1

Wilkerson JT, Jacobson MZ, Malwitz A et al (2010) Analysis of emission data from global commercial aviation: 2004 and 2006. Atmos Chem Phys 10:6391-6408. https://doi.org/10.5194/ acp-10-6391-2010

WMO (1957) Meteorology - a three-dimensional science: Second session of the commission for aerology. WMO Bull 4:134-138

Xue D, Lu J, Sun L et al (2017) Local increase of anticyclonic wave activity over Northern Eurasia under amplified arctic warming. Geophys Res Lett 44:3299-3308. https://doi.org/10.1002/2017G L072649

Yang H, Waugh DW, Orbe C et al (2019) Large-scale transport into the arctic: the roles of the midlatitude jet and the hadley Cell. Atmos Chem Phys 19:5511-5528. https://doi.org/10.5194/ acp-19-5511-2019

Zolotov SY, Ippolitov II, Loginov SV (2018) Characteristics of the subtropical jet stream over the North Atlantic from reanalysis data. IOP Conf Ser Earth Environ Sci 211:012005. https://doi. org/10.1088/1755-1315/211/1/012005 